\title{
We love them anyway: outdoor environmental education programs from the accompanying teachers' perspective
}

\author{
Jan Cincera ${ }^{1}$ D $\cdot$ Jan Zalesak $^{1} \cdot$ Miloslav Kolenaty $^{2} \cdot$ Petra Simonova $^{1}$. \\ Bruce Johnson ${ }^{3}$
}

Accepted: 10 June 2021 / Published online: 24 August 2021

(c) Outdoor Education Australia 2021

\begin{abstract}
The ways in which residential outdoor environmental education programs are perceived by the teachers accompanying their elementary school students have rarely been investigated. In this study, interviews were conducted with 17 elementary school teachers who had participated in one of five selected residential programs in the Czech Republic in 2018 - 2019. As the findings show, all the teachers found the residential programs beneficial for their teaching. However, a majority of the teachers reported that the most significant outcome was the improvement in the students' interpersonal competence and in the relationship between the teachers and their students. Interestingly, the effect of the residential programs on developing the students' environmental understanding, attitudes, and values remained secondary or was questioned by the teachers. The aspect that the teachers appreciated most was the application of experiential learning methods providing emotional experiences for the students. The paper discusses the possible reasons for such perceptions of these programs and the implications for practice.
\end{abstract}

Keywords Outdoor environmental education · Teachers · Experiential learning · Residential programs $\cdot$ Teacher satisfaction

Jan Cincera

cincera@mail.muni.cz

1 Department of Environmental Studies, Faculty of Social Studies, Masaryk University, Jostova 10, Brno 602 00, Czech Republic

2 Department of Environmental Studies, Faculty of Environment, Jan Evangelista Purkyně University in Ústí Nad Labem, 40096 Ústí nad Labem, Czech Republic

3 College of Education, University of Arizona, Tucson, AZ, USA 


\section{Introduction}

Outdoor environmental education is usually seen as a subset of environmental education or as a combination of outdoor and environmental education, encompassing learning activities occurring outdoors. Outdoor environmental education is often provided in the form of residential two-to-five-day programs which are offered by outdoor environmental education centers to schools (Abdullah, 2017; Mullenbach et al., 2019; Reese, 2019).

The Czech Republic has a long tradition of both outdoor education and outdoor environmental education. Czech outdoor education has its roots in the early twentieth century. In spite of political restrictions, this type of education persisted until the democratic revolution in 1989, mainly in the form of summer camps and outdoor residential programs focused on developing inter- and intra-personal competence (Jirásek \& Turcova, 2017, Jirásek et al., 2016, Kudláček et al., 2009). Since its beginnings in the non-formal education movement, environmental education has evolved into a closely cooperating network of environmental education centers offering both school-based and residential outdoor programs. Today, both movements, outdoor education and environmental education, are widespread in this country and influence each other.

While outdoor education programs still typically focus on developing intraand inter-personal competence, they often include the ekistic perspective, applying it primarily as a way of understanding the human-nature relationship (Priest, 1986). Similarly, while the programs offered by outdoor environmental education centers typically emphasize ecosystem and ekistic perspectives, they often include activities that facilitate the development of the participating students' cooperation and communication competence (Kulich, 2006; Máchal, 2000). All the intra-, inter-, ekistic and ecosystem perspectives are part of the national curricula and, based on this, schools are motivated to participate in these kinds of programs.

The effectiveness of these programs regarding developing students' environmental knowledge, attitudes, and motivation toward responsible behavior has been repeatedly evaluated (Dettmann-Easler \& Pease, 1999; Stern et al., 2008; Szczytko et al., 2018). In addition, the roles outdoor program practitioners play, the necessary skills and techniques they teach, and the challenges they face in their effort to achieve the program goals have been widely described (Cooper, 1994; Martin, 1999; Nicol, 2002-2003; Schwarz, 2002, 2005; Thomas, 2004, 2005 , 2010). However, the perspectives of the teachers accompanying the students during the outdoor programs have remained understudied in both the national and international contexts.

The accompanying teachers play an instrumental role in residential outdoor environmental education programs. First, the teachers are often the ones who decide whether the class will participate and the ones who choose a particular program. Program selection may be affected by external factors, such as program cost or geographical distance (Ballantyne \& Packer, 2006; Činčera \& Havlíček, 2016; SmithSebasto, 2006). Prioritizing lower-priced residential programs may lead teachers to 
select ones of insufficient length and weak quality or effectiveness (Rickinson et al., 2004; Zelezny, 1999). Further, several authors have suggested that the quality of program selection by some teachers may be negatively influenced by their inadequate environmental literacy or their poor understanding of environmental education (Desjean-Perrotta et al., 2008; Moseley et al., 2010; Yavetz et al., 2014). At the same time, other authors have found that the majority of teachers perceived outdoor activities and field trips as important for environmental education, even if they did not always use them with their students (Ko \& Lee, 2003; Mosothwane, 2002; SmithSebasto, 2006).

Importantly, it is the teachers' task to link the residential outdoor programs with the school curricula. Students' learning is supported by their preparedness for the program and the program content, as well as by the follow-up activities at school (Dettmann-Easler \& Pease, 1999; Rickinson et al., 2004; Smith-Sebasto \& Cavern, 2006). Therefore, the teachers' active involvement in the planning and implementation of the program is important. To achieve this, extensive knowledge of the outdoor setting and the particular locality is required to effectively connect the outdoor program with the regular school curricula (Brookes, 2002). However, in many cases, the program is planned and organized exclusively by the outdoor centers without the teachers' active participation (Menzies et al., 2017; Kendall \& Rodger, 2015).

Additionally, it is often the teachers who take on all of the responsibility and the burden of the organizational issues, from doing the paperwork to communicating with the students, the parents, and the program providers. This is, in many cases (at least in the Czech Republic), extra work on top of their usual teaching obligations (Buchal, 2010). The pre-requisites for smooth organization and meaningful outcomes of outdoor environmental programs include supportive administration, management, and parents, as well as a climate of openness at the school (Anderson, 1982; Hoy 1990) and an articulated emphasis on outdoor or environmental education within the school goals, values, and mission (Stolp, 1994).

According to Ballantyne and Packer (2006), three models of cooperation between outdoor environmental education centers and schools may be found in the field: the destination model, the expert/advisory model, and the partnership model. In the destination model, schools tend to see the centers as external program providers, valued for the attractiveness of their locality or specific pedagogical techniques. In the expert/advisory model, schools focus on getting inspiration in environmental management or teaching methods from the centers. Ballantyne and Packer (2006) recommend the partnership model which involves long-term cooperation between the schools and the centers. In this model, the on-site program is incorporated into the curriculum, broadening the learning experience and affecting the entire school community.

Moreover, the accompanying teachers may be directly involved in the outdoor program (Kendall \& Rodger, 2015; Menzies et al., 2017). The process of interaction between the teachers and the program leaders may be both beneficial and challenging. Slattery and Lugg (2002) analyzed the mutual expectations of teachers and the park rangers responsible for interpretative programs, and they found that the rangers appreciated sharing their responsibility for the program with the teachers. However, they sometimes found the teachers' approach to be inadequate. For example, while 
the rangers wanted to highlight the environmental value of the national park, the teachers focused more on the park's recreational value, treating "the park visit as an end in itself" (p. 52). As a result, some rangers were concerned that the teachers' emphasis on recreational activities may overshadow the environmental value of the park. According to the teachers, the rangers had different opportunities for working with students than they usually had in formal educational settings. Indeed, the division of facilitation and leadership roles and aims between the teachers and the program leaders can become an issue, and programs can be more effective when this division is clarified in advance (Gass and Stevens, 2007; Thomas, 2010).

In the Czech Republic, residential programs are organized by most elementary schools; and in most cases they do so without any external assistance. When a program provided by an outdoor center is chosen, the cooperation between the school and the center is often based on the destination model, with the schools seen as clients who contract external services (Ballantyne \& Packer, 2006; Činčera et al., 2016; Činčera and Havlíček, 2016; Činčera, 2013).

As part of broader research on residential outdoor environmental education programs in the Czech Republic, this paper investigates the teachers' perceptions of these programs. The paper is based on a study that was conducted with the teachers accompanying their students in five selected programs offered by residential outdoor environmental education centers in 2018 and 2019. We sought to answer the following questions:

- How did the teachers evaluate the instructional strategies applied in the residential programs?

- According to the teachers, what benefits did these programs bring to their students in terms of learning and competence development?

\section{Methodology}

To answer the above research questions, interviews were conducted with 17 elementary school teachers who accompanied their students in a residential outdoor environmental education program in 2018 or 2019. Before the interviews, five different residential programs were selected which focused on nine-to-twelveyear-old students. The selection process started with identifying environmental education centers which offer residential programs. Of 18 centers, those that did not offer three-to-five-day programs for elementary school students were excluded. Further, the existing three-to-five-day programs offered by the centers were preliminarily assessed. Programs were excluded from the study if they did not have clear educational aims and consisted of simply a set of outdoor activities, and when they did not focus on developing students' environmental values and behavior. This assessment was completed following discussion among members of the research team, using the information publicly available about the programs (online presentation). When needed, the research team asked the program providers for further information (detailed program description). In addition, the 
research team members built on their expert knowledge of the field and excluded programs whose quality could be disputed. In the last step, the selected centers were asked for cooperation in the research and the final sample consisted of those who agreed.

All of the selected programs shared some basic features. They aimed to promote environmental values and behavior, and focused on developing students' appreciation of the local natural area, on students' understanding of particular ecological processes (e.g., adaptation, succession), or on outdoor skills (e.g., making a fire).They also shared some important program elements, including being of three-to-five-day duration and being situated in a natural area. Moreover, the programs shared some other aspects not directly involved in the selection process: all of them utilized field trips, encouraged direct interaction with nature, and used experiential learning methods. Nevertheless, each program was organized by a different environmental education center. Therefore, despite their many similarities, the programs used different activities and differed somewhat in the level of the teachers' and the students' involvement in the decision-making.

For the research, the plan was to interview all of the teachers who accompanied their students during the five selected programs in the period from September 2018 to June 2020 . However, due to the situation caused by the Coronavirus pandemic, the residential programs planned for Spring 2020 were canceled, which negatively affected the number of respondents. Of the 21 teachers who accompanied the elementary school groups that participated in the selected programs during the observed period, 4 teachers declined to be interviewed because of lack of time or interest. Altogether, 17 teachers (13 female, 4 male) who accompanied students during the selected programs were interviewed. Most of the respondents were highly experienced teachers, with more than 15 years of practice. Only one of the interviewed teachers had just 5 years of practice and so could be considered a junior teacher.

Interviewing teachers who participated in different programs allowed a diversity of perspectives to be obtained. However, as some of the programs were offered more often than others, the number of respondents per each program varied from two to seven.

As a result of the existing limitations, a caution regarding the interpretation of the findings must be recommended. The research did not aim to evaluate the particular programs (for this reason, no specific information about the programs is included). Neither did the research intend to generalize the findings and apply them to the many diverse types of outdoor environmental education programs. Moreover, it is possible that the reason some teachers declined to be interviewed could have been their dissatisfaction with the program. In light of this, the findings should be regarded as an effort to identify certain potential patterns emerging in the teachers' perspectives on this educational area, with the aim to open a continuing discussion.

Due to the Coronavirus pandemic, 7 of the interviews had to be done by phone. In the interviews, a semi-structured, flexible format was used, allowing the interviewers to react to the respondents' ideas (e.g., the respondents were asked additional 
questions to clarify their previous answers, provide other examples, etc.) (Patton, 2014). The interviews followed these general guidelines:

- The respondents' reflections on the selected program (e.g., When you reflect on program X, what was your strongest experience?).

- The respondents' description of the circumstances influencing their selection of the program and of their expectations related to this program (e.g., When you were selecting this program, what did you expect to come out of this choice?).

- The respondents' evaluation of the strategies applied in the selected program (e.g., Based on your opinion, what are the strongest elements of the program? What do you appreciate most about the program? What would you recommend to be changed?).

- The respondents' perceptions of the effects of the selected program on the students' learning and the way the respondents connected the program with their school curricula (e.g., What did your students learn in the program? How did you link the program with what your students learn in school?).

All of the interviews were recorded and transcribed (Patton, 2014). To protect the respondents' anonymity, their names were coded as R1-R17. For the analyses, all of the data segments bearing a distinctive meaning for open-coding were selected. The codes were further grouped into broader categories partly corresponding with the pre-determined themes of the interviews, according to the research questions and interview topics (e.g., effects, expectations) (Patton, 2014; Saldana, 2015). Apart from these categories, several new categories emerged from the data (e.g., instructional strategies, leaders \& settings, etc.) (Saldana, 2015). For this paper, the categories were organized into three main themes which provided answers to the research questions: general assessment, crucial features, and perceived effects.

This study is part of a broader research project analyzing these five outdoor environmental education programs from more perspectives. Based on previous research cooperation, one of the researchers knew all of the centers' managers and some of the leaders, which could be a potential source of bias. All of the respondents and all the representatives of the involved centers agreed to the research, and the research was approved by the university board.

\section{Findings}

\section{General assessment: (Almost) uncritical approval}

While for some of the respondents it was the first time they participated in the particular program, most of the teachers had accompanied their students repeatedly. At some of the schools, the program had become a tradition, with the teachers reportedly getting sent by their school principal. In other cases, the teachers received a recommendation for the program from someone else.

Most of the teachers seemed to interpret their involvement in the program in accordance with the destination model described by Ballantyne and Packer 
(2006), i.e., they saw the program as a service provided by an external organization. Some of the respondents mentioned that their role as an accompanying teacher in the program was very demanding because of their responsibility for the students all the time, every day, and because of the associated paperwork. One of the respondents suggested that the programs should be completely prepared by the outdoor centers to minimize any additional work for the teachers.

Regardless of the context of the teachers' participation, all of the respondents were highly satisfied with the programs. Most were unable to identify any negative aspects, and when asked, they recommended only minor, mostly "technical" improvements, such as shortening the reflection sessions, lowering the intensity of the program, or including more one-day or two-day field trips.

The reasons for the respondents' satisfaction included their feeling that the program was perfectly prepared, the program leaders were experienced experts who applied good pedagogical methods (e.g., games, experiential activities), and the students loved the program. Some of the respondents also generalized their experience and suggested that these programs were so important that they should be provided to everyone:

These [=outdoor environmental education] programs are so necessary. And it is a pity that all children cannot experience them because there are so few of these centers. For example, to X (name of the outdoor center), you must make a reservation three years in advance.... A lot of teachers, not focused on science, they tell you, so you take the children for a week away, they will not do the subjects they would have in school, but here it has a different benefit. ( $\mathrm{R} 1,6^{\mathrm{th}}$-grade teacher, female, 18 years of practice)

I am so very happy I could experience it with my students. (R2, $6^{\text {th }}$-grade teacher, male, 11 years of practice)

\section{Instructional strategies from the accompanying teachers' perspective: providing emotional experiences and facilitating experiential learning}

Two features emerged as the most often mentioned and the most important ones for the respondents' satisfaction: providing emotional experiences and facilitating experiential learning. While these terms may seem to be connected, the respondents differentiated between them.

Highlighting the residential programs as a source of experiences, the respondents had in mind strong, emotionally-loaded activities or unexpected situations. They linked these experiences with adventures, students' excitement, and longlasting memories. From their perspective, the programs offered something unusual and attractive, something that, for some of the respondents, was the very reason they accompanied their students in the program.

Teacher: For sure, as we worked in the night, as they walked with the torches, and as they went to search for the keys. This is what I have got from the feedback that had really engaged them. 
Interviewer: OK, and why do you think it was the strongest experience for them?

Teacher: Because they are not used to being in nature in the evening. Plus, the live fire, it was a very strong emotional experience, I think. (R16, $4^{\text {th }}$-grade teacher, female, more than 30 years of practice)

The teachers' concept of these experiences differed from their concept of experiential learning. While the respondents perceived "emotional experiences" as memorable moments (such as sitting around the campfire) potentially significant for the students in the long-term, they mostly associated "experiential learning" with active methods intentionally applied by program leaders to develop students' ecological understanding and their outdoor or interpersonal competence. Based on this, the accompanying teachers' concept of "experiential learning" differed from how this approach is defined by Kolb and other authors (Kolb, 1984; Parry \& Allison, 2020; Prouty et al., 2006) assuming any experience may become the source of learning, provided it is properly presented.

Experiential learning was the most often mentioned aspect that the respondents appreciated about their residential program. Specifically, they appreciated that the learning occurred in outdoor settings, that it was illustrative, based on doing things and playing games, and that it encouraged students' cooperation.

So, they learn, but they do not consider it learning. They get information, sure, they do not remember everything, but they sort it out in their little brains. And they are in the middle of natural activities, they touch everything, try, practice ... which they need, you have no chance to do this in school. (R4, $7^{\text {th }}$-grade teacher, female, 25 years of practice)

In addition to the highly appreciated concepts of experiences and experiential learning, some of the respondents also highlighted other qualities of the programs. Four of the teachers appreciated the interesting framing of their program which supported students' motivation and interlinked the program activities. Other teachers mentioned good interlinking of the place, the program, and the program leaders, or the freedom provided to the students to make independent decisions. Two respondents appreciated the overall good organization of their program or the high quality of the program leaders.

\section{Perceived effects: major social, minor green}

Despite the fact that the main focus of the programs was on developing students' environmental values and behavior, the most frequently mentioned effects, as perceived by the accompanying teachers, were inter- and intrapersonal competencies. These effects were usually connected with the teachers' expectations. Most of them reported that they had chosen the program because they expected that the students would learn to cooperate with one another and the program would improve group cohesion, and because they wanted to get to know their students better.

This is also how the accompanying teachers reflected on the main benefits of the program. Almost all of the respondents reported the programs' positive 
effects on the class climate and on the relationships among the students. According to the teachers, the programs helped to develop the students' intrapersonal competencies, mainly by exposing them to unusual situations and challenges. The novelty of the situations encouraged students to play new roles in their class and so to change their position in the group. Last but not least, the experience helped the teachers to learn more about their students, their social competence, and their needs.

Well, they are quieter now, and, somehow, I feel better in the class because I have got to know them differently. And it made a very positive impact on the school climate, even if I cannot say why it changed so quickly. That they left this school environment. (R5, $5^{\text {th }}$-grade teacher, female, 9 years of practice) The highest benefit for me is that the class learns more about itself, learns to be together, learns to cooperate in the group. (R2, $6^{\text {th }}$-grade teacher, male, 11 years of practice)

In comparison, the effect of the programs on environmental understanding, attitudes, and behavior was perceived as minor. Some of the teachers questioned the effectiveness of the program regarding learning science and ecological concepts, and assumed that it could be better done in the classroom:

OK, so they do a kind of learning ... it is different for them, and so enjoyable for some of them, while others may struggle with it because they like frontal [lecture-style] teaching. However, I think that the effect may be powerful in terms of days, but not in the long term. (R6, $6^{\text {th }}$-grade teacher, male, 21 years of practice)

Well, some of them keep something but I think if it is not further developed, the week is still a short time, and so they slip back to the stereotypes. (R7, $6^{\text {th }}$-grade teacher, female, 30 years of practice)

However, this skepticism was not shared by all of the respondents. Some of them believed that the program helped to develop students' environmental attitudes, outdoor skills, or scientific knowledge. Two of the respondents mentioned that the program probably helped students to sort out their environmental beliefs or to see things from a different perspective:

I find it quite good [to show] the real impact of the individual activities. Like when we dealt with the impact on the countryside and they saw the dry streams, they were quite scared. When one discusses it somewhere in the classroom, even if I show them a movie, it is still far away. But when they were walking through the countryside that means something to them, so I guess it was quite important to them. So that they can feel it themselves. (R2, $6^{\text {th }}$ grade teacher, male, 11 years of practice)

Two of the respondents also believed that the program could have had a positive impact on the students' environmental behavior by supporting more respectful social norms. 
They realized that nature, the resources are not unlimited ... So indeed, they (started to) take care more, to look around and see that nature must be protected, not only exploited. (R8, $5^{\text {th }}$ grade teacher, male, 32 years of practice)

However, other respondents questioned this type of effect, claiming that the students' behavior was developed by their family values and the program could not change that (see Cheng \& Monroe, 2012).

To expand beyond the program activities, some of the teachers did some followup or reflection on the program activities back at school. However, the reflections seemed to be spontaneous, emerging from the learning situations in the class, rather than being carefully planned.

\section{Discussion}

The findings show a mixture of positive and challenging aspects in the way the accompanying teachers perceived their residential programs. It is likely that, due to the methodological limitations, the group was skewed toward teachers with an affinity for this kind of programs. Nevertheless, the lack of negative statements in the respondents' overall evaluation of the programs supports the programs' importance to the teachers. In light of this, the residential centers provide a service much appreciated by schools.

While the programs aimed to develop environmental knowledge, skills, attitudes, and behavior, for most of the accompanying teachers these effects played only a secondary role. Despite the programs' aims and the program leaders' intentions to develop students' environmental understanding, values, behavior, or outdoor skills, the teachers viewed the programs mainly as an opportunity to develop the relationships among and with their students. It should be said that the potential benefits in this area are in themselves valuable educational goals. In addition, well-functioning relationships in the group of students can be important pre-requisites for achieving a number of environmental education goals, and positive school or classroom climate can help with the adoption of environmental and sustainable solutions (Higgs \& McMillan, 2006). However, such benefits also seem to be less important in the context of the mission of the environmental education centers. It could be said that while the programs focus on learning in nature, about nature, and for nature, most of the teachers interpret them as promoting learning in nature, about students, and for strengthening their relationships.

This difference may be caused by a combination of interconnected factors. Regarding the Ballantyne and Packer (2006) typology, the accompanying teachers seemed more inclined toward the destination model of a school-outdoor center partnership than toward a higher level of involvement in the program planning and implementation. It also appeared that the teachers did not focus so much on linking the program with their curricula. This may result in the programs' diminished effects on the students' learning (Dettmann-Easler and Pease, 1999; Rickinson et al., 2004; Smith-Sebasto \& Cavern, 2006). 
The fact that the involvement of the accompanying teachers in the programs is limited and that the teachers do not link the program content with their school practice may correspond with the overall, skeptical approach of some of the teachers had toward the effectiveness of the programs regarding teaching science and ecological concepts. This may be further influenced by the teachers' initial expectations which favor other benefits of the programs. When the teachers do not expect the students to learn much from the program, are not involved in the planning of the program, and do not develop activities to follow up on the learned concepts back in school, the teachers may be unintentionally contributing to having their limited expectations fulfilled.

Another explanation of the teachers' skepticism regarding the programs' effects as related to environmental education may be connected with the way this education is presented by the centers. It is possible that the centers do not properly communicate to the teachers the intended effects of the program on students' environmental learning. As a result, some of the teachers form their expectations based on their potentially limited concepts of environmental education (Desjean-Perrotta et al., 2008; Moseley et al., 2010; Yavetz et al., 2014).

The skepticism expressed by some of the accompanying teachers contrasts with their overall positive assessment of the learning process facilitated by the program leaders. It is interesting to see that while the teachers appreciated the quality of the programs, some of them did not see their effectiveness. However, the findings also reflect differences among the respondents as some of them not only reflected on the impact of the programs on the students' learning but also identified the strategies crucial for the facilitation of experiential learning. In light of this, better communication of both the programs' intended effects and the programs' learning strategies may help the teachers to improve their understanding of outdoor environmental education programs.

Increased involvement of the accompanying teachers in the process of designing and implementing the programs is another potentially helpful strategy (Kendall \& Rodger, 2015; Menzies et al., 2017). However, the findings do not indicate that the teachers are motivated to replace the destination model described by Ballantyne and Packer (2006). The reasons may be systemic, based on the huge amount of paperwork and other responsibilities placed on the teachers who get involved in this kind of program. In light of their already positive appreciation, re-considering the legal framework that defines the teachers' duties in the outdoor programs, based on the country-specific context, could be a sound strategy for supporting the other models of the school-center relationship.

The importance of providing strong experiences is another finding that deserves consideration. Incorporating strong, potentially transformative, experiences in outdoor environmental education programs has been highlighted by several authors (Van Matre, 1990; Wohlers \& Johnson, 2003). The elements of novelty and adventure, reported by the teachers we interviewed, seem to resonate with the motivation of students at the elementary-school age (Sobel, 2008). This brings an interesting perspective on the programs' aims. While the aims of all of the programs were defined in terms of developing students' environmental understanding, skills, values, and behavior, from the teachers' perspective, other, harder-to-measure goals were of 
higher importance. Such strong experiences are difficult to organize at school but, at the same time, are highly valued by students. In the context of the paradox that the teachers appreciate the experiential learning process but question its educational effect, it may mean that, for teachers, the significance of experiential learning lies in providing a transformative experience rather than in developing students' environmentally-related competence. This corresponds with the interpretation of experiential learning expressed by some of the program leaders, too (Činčera et al., 2020).

The accompanying teachers' perspectives on outdoor environmental education programs may differ from the intentions of the programs' designers and leaders. The process of mutual interaction of the two sides may prove to be both beneficial and challenging (Slattery and Lugg, 2002).

\section{Conclusion}

The perceptions of accompanying teachers' on residential outdoor environmental education programs and their feelings and expectations regarding these programs are still not perfectly clear. In light of the teachers' role not only in choosing a particular program but also in involving their students in preparatory and follow-up activities, this area is worthy of further investigation.

Based on the findings of this study, it can be concluded that the accompanying perceived the programs as highly beneficial and important. However, their views regarding how the students benefited from the programs and what impact the programs had on the students' environmental literacy often differed from the intentions of the programs' designers. Although the investigated programs focused on developing students' environmental understanding, attitudes, skills, and behavior, many of the teachers seemed to interpret them mainly as an opportunity to cultivate the students' social competencies. Because of this, improving the communication between the outdoor environmental education centers and the schools could help in gaining better mutual understanding of the other stakeholders' needs and aims.

While a closer relationship between the schools and the centers might improve the programs' effectiveness, most of the teachers do not seem to be very motivated to become more involved and would rather maintain the prevailing destination model of cooperation. It is possible that deeper, systemic reasons defining the teachers' duties in the programs are at play. In light of this, critical analyses and revisions of the broader legal context may be necessary in order to promote positive changes in school-center relationships.

Furthermore, the findings of this study raise questions crucial for reconsidering school-center relationships. The differences in the two sides' agendas and the constraints limiting the accompanying teachers' ability to exploit the full potential of the residential environmental programs call for a pragmatic approach balancing theorybased recommendations with their practical boundaries. For example, while the destination model (Ballantyne \& Packer, 2006) offers only a limited educational potential, it still may be the only choice for the majority of teachers who are struggling with their many other duties. Similarly, while linking the residential programs with school curricula by including pre- and follow-up activities is clearly beneficial for 
students' learning (Dettman-Easler and Pease, 1999; Rickinson et al., 2004; SmithSebasto \& Cavern, 2006), the program providers should be able to flexibly adjust their programs for those schools where such activities cannot be implemented.

These issues are important and need to be considered in the ongoing process of shaping both theory and practice in outdoor environmental education.

Funding This article is one of the outputs of the project Promoting Behavioral and Value Change through Outdoor Environmental Education which is supported by grant no. GA18-15374S provided by the Czech Science Foundation.

\section{Declarations}

Conflicts of interest The authors declare that they have no conflict of interest.

\section{References}

Abdullah, S. I. S. S. (2017). An Investigation into the Influence of Outdoor Environmental Education Courses on the Environmental Attitude and Behaviors of Malaysian Participants: A Life History Approach. The University of Edinburgh.

Anderson, C. S. (1982). The search for school climate: A review of the research. Review of Educational Research, 52(3), 368-420. https://doi.org/10.3102/00346543052003368

Ballantyne, R., \& Packer, J. (2006). Promoting learning for sustainability: Principals' perceptions of the role of outdoor and environmental education centres. Australian Journal of Environmental Education, 22(1), 15-29. https://doi.org/10.1017/S0814062600001622.

Brookes, A. (2002). Lost in the Australian bush: Outdoor education as curriculum. Journal of Curriculum Studies, 34(4), 405-425. https://doi.org/10.1080/00220270110101805

Buchal, J. (2010). Škola v přirodě z pohledu manažera. Univerzita Karlova.

Cheng, J.C.-H., \& Monroe, M. C. (2012). Connection to nature: Children's affective attitude toward nature. Environment and Behavior, 44(180), 31-49. https://doi.org/10.1177/0013916510385082

Činčera, J. (2013). Střediska ekologické výchovy mezi teorií a praxí. BEZK, Agentura Koniklec, \& Masarykova univerzita.

Činčera, J., \& Havlíček, F. (2016). Environmental education centers from the teachers' perspective. Envigogika, 11(2). https://doi.org/10.14712/18023061.534

Činčera, J., Jančaříková, K., Matějček, T., Šimonová, P., Bartoš, J., Lupač, M., \& Broukalová, L. (2016). Environmentální výchova z\&nbsp;pohledu učitelů. BEZK, Agentura Koniklec, \& Masarykova univerzita.

Činčera, J., Johnson, B., Kroufek, R., Kolenatý, M., \& Šimonová, P. (2020). Frames in outdoor environmental education programs: What we communicate and why we think it matters. Sustainability, 12(11), 4451. https://doi.org/10.3390/su12114451

Cooper, G. (1994). The role of outdoor education in education for the 21 st century. Journal for Adventure Education and Outdoor Leadership, 11(2), 9-12.

Desjean-Perrotta, B., Moseley, C., \& Cantu, L. E. (2008). Preservice teachers' perceptions of the environment: Does ethnicity or dominant residential experience matter? The Journal of Environmental Education, 39(2), 21-32. https://doi.org/10.3200/JOEE.39.2.21-32

Dettmann-Easler, D., \& Pease, J. L. (1999). Evaluating the effectiveness of residential environmental education programs in fostering positive attitudes toward wildlife. The Journal of Environmental Education, 31(1), 33-39. https://doi.org/10.1080/00958969909598630

Gass, M. A., \& Stevens, C. A. (2007). Facilitating the adventure process. In D. Prouty, J. Panicucci, \& R. Collinson (Eds.), Adventure education: Theory and applications (pp. 101-123). Human Kinetics. 
Higgs, A. L., \& McMillan, V. M. (2006). Teaching through modelling: Four school experiences in sustainability education. The Journal of Environmental Education, 38(1), 39-53. https://doi.org/10. 3200/JOEE.38.1.39-53

Jirásek, I., Plevová, I., Jirásková, M., \& Dvořáčková, A. (2016). Experiential and outdoor education: The participant experience shared through mind maps. Studies in Continuing Education, 38(3), 334354. https://doi.org/10.1080/0158037X.2016.1141762

Jirásek, I., \& Turcova, I. (2017). The Czech approach to outdoor adventure and experiential education: The influence of Jaroslav Foglar's work the Czech approach to outdoor adventure and experiential. Journal of Adventure Education and Outdoor Learning, 17(4), 321-337. https://doi. org/10.1080/14729679.2017.1344557

Kendall, S., \& Rodger, J. (2015). Evaluation of Learning Away: Final. Report Paul Hamlyn Foundation.

Ko, A. C., \& Lee, J. C. (2003). Teachers' perceptions of teaching environmental issues within the science curriculum : A Hong Kong perspective. Journal of Science Education and Technology, 12(3), 187-204. https://doi.org/10.1023/A:1025094122118

Kolb, D. (1984). Experiential Learning. Prentice Hall.

Kudláček, M., Bocarro, J. N., Jirásek, I., \& Hanuš, R. (2009). The Czech way of inclusion through an experiential education framework. Journal of Experiential Education, 32(1), 14-27. https://doi. org/10.1177/105382590903200103

Kulich, J. (2006). Co jsou a kde se vzala střediska ekologické výchovy, ekocentra, ekologické poradny. Bedrník, 4(2), 12-14.

Máchal, A. (2000). Praktická ekologická výchova. Rezekvítek.

Martin, P. (1999). Critical outdoor education and nature as friend. In J. C. Miles, \& S. Priest (Eds.), Adventure programming (pp. 463-471). Venture.

Menzies, L., Bowen-Viner, K., \& Shaw, B. (2017). Learning Away: The state of school residentials in England 2017. LKM.

Moseley, C., Desjean-Perrotta, B., \& Utley, J. (2010). The Draw-An-Environment Test Rubric (DAET-R): Exploring pre-service teachers' mental models of the environment. Environmental Education Research, 16(2), 189-208. https://doi.org/10.1080/13504620903548674

Mosothwane, M. (2002). Pre-service teacher's conceptions of environmental education. Research in Education, 68(1), 26-40. https://doi.org/10.7227/RIE.68.3

Mullenbach, L. E., Andrejewski, R. G., \& Mowen, A. J. (2019). Connecting children to nature through residential outdoor environmental education. Environmental Education Research, 25(3), 365-374. https://doi.org/10.1080/13504622.2018.1458215

Nicol, R. (2002-2003). Outdoor education: Research topic or universal value? Part one, two and three. Journal of Adventure Education and Outdoor Learning, 2(1), 29-41; 2(2), 85-99; 3(1), 11-28.

Parry, J., \& Allison, P. (Eds.). (2020). Experiential learning and outdoor education. Routledge.

Patton, M. Q. (2014). Qualitative Research \& Evaluation Methods. Sage.

Priest, S. (1986). Redefining outdoor education: A matter of many relationships. The Journal of Environmental Education, 17(3), 13-15. https://doi.org/10.1080/00958964.1986.9941413

Prouty, D., Panicucci, J., \& Collinson, R. (2006). Adventure Education. Theory and Applications. Human Kinetics.

Reese, R. F. (2019). A qualitative exploration of the barriers and bridges to accessing communitybased K-12 outdoor environmental education programming. Journal of Outdoor and Environmental Education, 22(1), 21-37. https://doi.org/10.1007/s42322-018-0019-4

Rickinson, M., Dillon, J., Teamey, K., Morris, M., Choi, M. Y., Sanders, D., \& Benefield, P. (2004). A review of research on outdoor learning. National Foundation for Educational Research. King's College London. Retrieved from https://www.informalscience.org/sites/default/files/Review\% 20of\%20research\%20on\%20outdoor\%20learning.pdf. Accessed 1 June 2020

Saldana, J. (2015). The coding manual for qualitative researchers. Sage.

Schwarz, R. (2002). The skilled facilitator: A comprehensive resource for consultants, facilitators, managers, trainers, and coaches. Jossey-Bass.

Schwarz, R. (2005). Using facilitative skills in different roles. In R. Schwarz, \& A. Davidson (Eds.), The skilled facilitator fieldbook: Tips, tools, and tested methods for consultants, facilitators, managers, trainers, and coaches (pp. 27-32). Jossey-Bass.

Slattery, D. A., \& Lugg, A. (2002). If they treated the whole world like a national park : Environmental education by teachers and rangers. Australian Journal of Environmental Education, 18, 47-55. 
Smith-Sebasto, N., \& Cavern, L. (2006). Effects of pre- and posttrip activities associated with a residential environmental education experience on students' attitudes toward the environment. The Journal of Environmental Education, 37(4), 3-17. https://doi.org/10.3200/JOEE.37.4.3-17

Smith-Sebasto, N. J. (2006). A reinvestigation of teachers' motivations toward and perceptions of residential environmental education: A case study of the New Jersey school of conservation. The Journal of Environmental Education, 38(4), 34-43. https://doi.org/10.3200/JOEE.38.4.34-42

Sobel, D. (2008). Childhood and Nature: Design Principles for Educators. Stenhouse Publishers.

Stern, M. J., Powell, R. B., \& Ardoin, N. M. (2008). What difference does it make? Assessing outcomes from participation in a residential environmental education program. The Journal of Environmental Education, 39(4), 31-43. https://doi.org/10.3200/JOEE.39.4.31-43

Stolp, S. (1994). Leadership for School Culture. ERIC Digest, 91.

Szczytko, R., Carrier, S. J., \& Stevenson, K. T. (2018). Impacts of outdoor environmental education on teacher reports of attention, behavior, and learning outcomes for students with emotional, cognitive, and behavioral disabilities. Frontiers in Education, 3, 1-10. https://doi.org/10.3389/feduc.2018. 00046

Thomas, G. J. (2004). A typology of approaches to facilitator education. Journal of Experiential Education, 27(2), 123-140. https://doi.org/10.1177/105382590402700202

Thomas, G. J. (2005). Traditional adventure activities in outdoor environmental education. Australian Journal of Outdoor Education, 9(1), 31-39. https://doi.org/10.1007/BF03400810

Thomas, G. J. (2010). Facilitator, teacher, or leader? Managing conflicting roles in outdoor education. Journal of Experiential Education, 32(3), 239-254. https://doi.org/10.1177/105382590903200305

Van Matre, S. (1990). Earth education: A New Beginning. The Institute for Earth Education.

Wohlers, L., \& Johnson, B. (2003). A Programmatic approach: Purposeful experiences. Zeitschrift Für Erlebnispädagogik, 23(5/6), 14-22.

Yavetz, B., Goldman, D., \& Pe'er, S. (2014). How do preservice teachers perceive 'environment' and its relevance to their area of teaching? Environmental Education Research, 20(3), 354-371. https://doi. org/10.1080/13504622.2013.803038

Zelezny, L. C. (1999). Educational Interventions That improve environmental behaviors: A meta-analysis. The Journal of Environmental Education, 31(1), 5-14. https://doi.org/10.1080/00958969909598627

Publisher's note Springer Nature remains neutral with regard to jurisdictional claims in published maps and institutional affiliations. 